\title{
Spontaneous pneumothorax caused by an inflammatory myofibroblastic tumor-like lesion in a 14-year-old girl: a case report
}

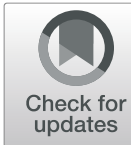

Hisayuki Miyagi ${ }^{1 *} \mathbb{D}$, Daisuke Ishii', Masatoshi Hirasawa' ${ }^{1}$, Shunsuke Yasuda ${ }^{2}$, Naohisa Toriumi ${ }^{3}$, Takeo Sarashina ${ }^{3}$, Mishie Tanino ${ }^{4}$, Mio Tanaka ${ }^{5}$, Yukichi Tanaka ${ }^{5}$ and Kazutoshi Miyamoto ${ }^{1}$

\begin{abstract}
Background: Spontaneous pneumothorax occurs more often in younger, slim, and shallow-chested men. Although less common, differential diagnoses for secondary pneumothorax in children are asthma, emphysematous blebs, catamenial pneumothorax, and others. We report a patient who presented with pneumothorax and was found to have an inflammatory myofibroblastic tumor (IMT)-like lesion, and present a review of the related literature.

Case presentation: A 14-year-old girl visited her physician for chest pain that developed while exercising. Although chest drainage was performed, the symptoms associated with a collapsed lung did not improve, and she was referred to our hospital. Computed tomography revealed the presence of a $19 \times 17-\mathrm{mm}$ cyst with a thick wall in the apex of the right lung. She was tested for infectious diseases, namely tuberculosis, but the results were not definitive. Catamenial pneumothorax was also suspected because she was menstruating when she presented to our hospital. As a therapeutic diagnosis, we performed a thoracoscopic partial resection of the right upper lobe of the lung. Three small openings were identified inside the cyst, suggesting connection with the bronchiole. The lesion was pathologically diagnosed as an IMT-like lesion. Considering the progress so far, we considered that the final diagnosis to be an IMT. The patient was discharged on postoperative day 3, and we have followed her for the past 6 months with no local recurrence or metastasis.

Conclusions: IMT is not uncommon in children. Therefore, this lesion should be considered as a possible diagnosis if children and young adults develop spontaneous pneumothorax.
\end{abstract}

Keywords: Spontaneous pneumothorax, Catamenial pneumothorax, Inflammatory myofibroblastic tumor (IMT), Anaplastic lymphoma kinase (ALK)

\section{Background}

Spontaneous pneumothorax occurs more often in the late teens, twenties, and thirties and more often in thin, shallow-chested men, and is usually classified as either traumatic or spontaneous. Trauma-related pneumothorax can be iatrogenic or accidental, and spontaneous pneumothorax can be primary or secondary. Although less common, differential diagnoses for secondary pneumothorax in

\footnotetext{
*Correspondence: miyagi@mvj.biglobe.ne.jp

'Division of Pediatric Surgery, Department of Surgery, Asahikawa Medical

University, 2-1-1-1 Midorigaoka Higashi, Asahikawa 078-8510, Japan

Full list of author information is available at the end of the article
}

children are asthma, emphysematous blebs, pulmonary tuberculosis, Langerhans cell histiocytosis, catamenial pneumothorax, Marfan syndrome, Ehlers-Danlos syndrome, Birt-Hogg-Dube syndrome, and angiosarcoma metastasis to the lung.

We report a patient who presented with pneumothorax and was found to have an inflammatory myofibroblastic tumor (IMT)-like lesion. We also reviewed the relevant literature. 


\section{Case presentation}

The patient was a 14-year-old girl who visited her physician for chest pain that developed while exercising. Upon detailed examination, right-sided pneumothorax was identified, and chest drainage was performed (Fig. 1). However, the symptoms associated with a collapsed lung did not improve, and she was referred to our hospital. Computed tomography revealed the presence of a $19 \times 17-\mathrm{mm}$ cyst with a thick wall in the apex of the right lung (Fig. 2). She was tested for infectious diseases, namely tuberculosis, but the results were not definitive (Table 1). Catamenial pneumothorax was also suspected because she was menstruating when she presented to our hospital. As a therapeutic diagnosis, we performed a thoracoscopic partial resection of the right upper lobe of the lung.

\section{Operation}

With the patient being under general anesthesia, at the left lateral position, we inserted a 5 -mm port on the mid-axillary line at the sixth intercostal space, followed by a $5-\mathrm{mm}$ port inserted on the posterior axillary line at the sixth intercostal space, and a $12-\mathrm{mm}$ port on the anterior axillary line at the fourth intercostal space. The thoracic cavity was thoroughly observed via thoracoscopy. No blueberry spots were found on the visceral pleura or the diaphragm (catamenial pneumothorax was considered negative). A ruptured cyst with a thick wall was found at the apex of the right lung, and three small openings were identified inside the cyst, suggesting communication with the bronchiole. The margin was sufficiently secured from the cyst, the lesion was excised using an Endo GIA $^{\mathrm{TM}}$ ultra-universal stapler (purple) (Covidien Surgical, Norwalk, CT), and the specimen was collected with an Endo Catch $^{\mathrm{TM}}$ Gold device (Covidien Surgical). A 20-Fr. thoracic drain was placed at the apex of the right lung through the first port to complete the operation. The operation time was $83 \mathrm{~min}$, and the blood loss volume was almost negligible (Fig. 3).

\section{Pathological diagnosis}

Pathological findings around the cyst wall included the infiltration of inflammatory cells, proliferation of fibroblasts, and the slightly dense distribution of mildly atypical spindle cells. Tumor cells proliferating around the cyst wall were anaplastic lymphoma kinase (ALK) (+), pan-tropomyosin receptor kinase (-), smooth muscle actin (SMA) (-), transducer-like enhancer of split $1(-)$, BCL6 corepressor gene (-), and alpha-internexin (-), using immunohistochemistry. In addition, no ALK split signal was observed using fluorescence in situ hybridization (Fig. 4c-e). Differential diagnoses were IMT and congenital peribronchial myofibroblastic tumor. However, congenital peribronchial myofibroblastic tumor is often identified and operated during infancy and has a different histopathology from IMT. Because SMA was negative in this case and ALK rearrangement could not be determined by fluorescence in situ hybridization, it was difficult to confirm IMT; nevertheless, the pathological diagnosis was an IMT-like lesion in our patient. Not all diagnostic materials were available for pathological diagnosis, so we based the final diagnosis of IMT on the clinical course including the patient background. The patient was discharged on postoperative day 3. We have followed her for the past 6 months and have not observed local recurrence or metastasis.

\section{Discussion}

The differential diagnoses for pneumothorax in children are asthma, emphysematous blebs, pulmonary tuberculosis, Langerhans cell histiocytosis, catamenial pneumothorax, Marfan syndrome, Ehlers-Danlos syndrome, Birt-Hogg-Dube syndrome, angiosarcoma metastasis to the lung, and others. To the best of our knowledge, no reports have discussed patients with IMT presenting with spontaneous pneumothorax.

An IMT is a mesenchymal neoplasm of intermediate malignancy (rarely metastasizing) according to the 2013 World Health Organization classification [1], which may develop in almost every organ [2]. Some authors reported
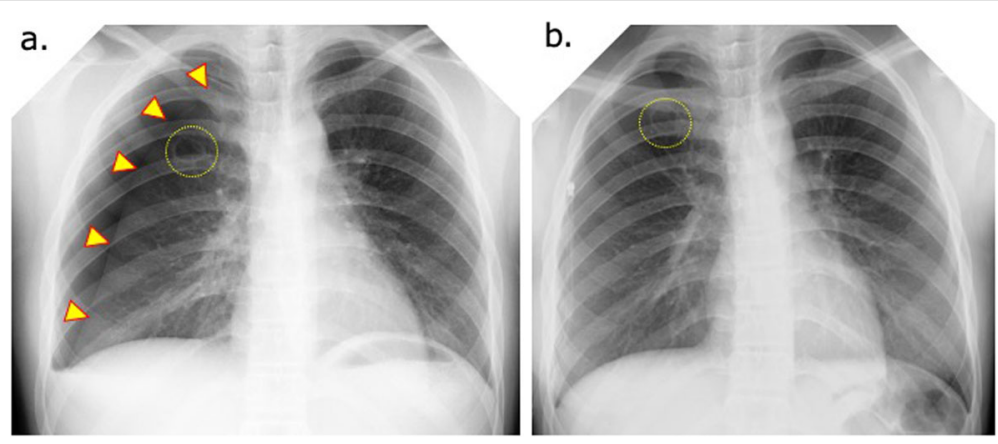

Fig. 1 Chest X-ray at the patient's first consultation. a Right pneumothorax is seen (yellow arrowheads). b At the previous hospital, placement of a thoracic drain for right pneumothorax did not improve the pneumothorax. Cyst wall thickening is visible in the upper right lung field (dashed yellow circle) 


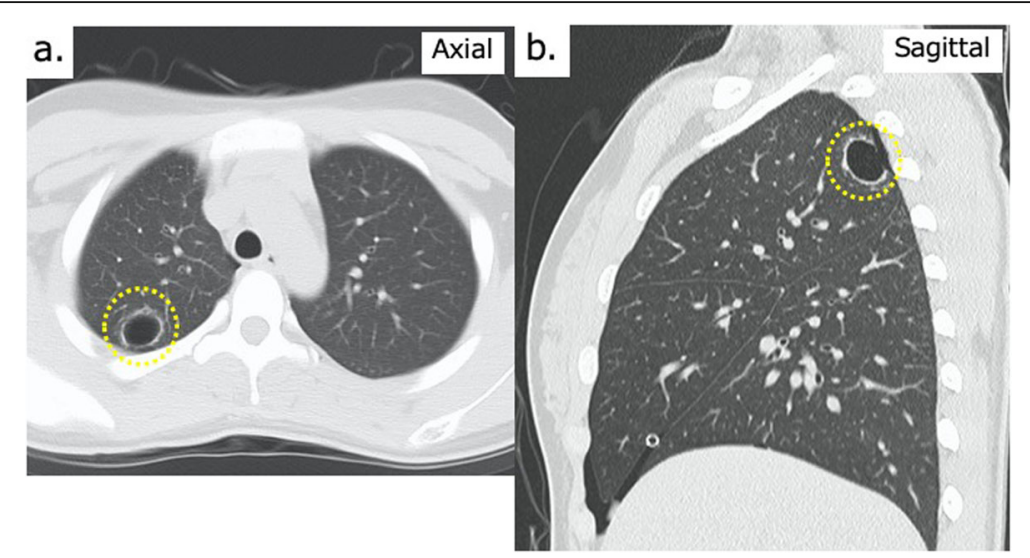

Fig. 2 Preoperative chest computed tomography images. a Axial view showing a $19 \times 17-\mathrm{cm}$ cystic lesion in the right upper lobe. Thickening of the cyst wall is visible (dashed yellow circle). $\mathbf{b}$ Sagittal view showing a cyst located posterior to the apex of the right lung (S1-2)

that an IMT in the lung is rare, with an incidence of $0.04 \%$ [3] to $0.3 \%$ [4]. Sex, race, and geographical location appear to play no role in the occurrence of IMT [4]. Cerfolio et al. reported that the median age of their patients was 47 years (range, 5-77 years) [4]. Others reported that IMT occurs in various anatomical locations, among which the lung is the most common site followed by the abdomen and retroperitoneum. IMT is generally more common in children and young adults and accounts for < $1 \%$ of all lung tumors [5]. Although IMT is defined as an intermediate tumor with the potential for local recurrence or metastasis, distant metastasis, most likely as extrapulmonary tumors, is seldom seen [6].

Tanaka et al. emphasized that IMTs are one of the most common primary lung tumors in children [7].

Table 1 The patient's laboratory data at admission

\begin{tabular}{llllll}
\hline TP & 7.7 & $\mathrm{~g} / \mathrm{dl}$ & WBC & 6890 & $/ \mu \mathrm{l}$ \\
Alb & 4.8 & $\mathrm{~g} / \mathrm{dl}$ & $\mathbf{H b}$ & 13.2 & $\mathrm{~g} / \mathrm{dl}$ \\
T-Bil & 0.5 & $\mathrm{mg} / \mathrm{dl}$ & $\mathbf{H t}$ & 39.0 & $\%$ \\
AST & 20 & $\mathrm{U} / \mathrm{l}$ & $\mathrm{PLT}$ & $40.3 \times 10^{4}$ & $/ \mu \mathrm{l}$ \\
YGT & 29 & $\mathrm{U} / \mathrm{l}$ & & & \\
AMY & 65 & $\mathrm{U} / \mathrm{l}$ & & & \\
BUN & 9.6 & $\mathrm{mg} / \mathrm{dl}$ & & & \\
Cre & 0.43 & $\mathrm{mg} / \mathrm{dl}$ & & & \\
UA & 3.6 & $\mathrm{mg} / \mathrm{dl}$ & & & \\
Na & 138 & $\mathrm{mEq} / \mathrm{l}$ & & & \\
K & 4.1 & $\mathrm{mEq} / \mathrm{l}$ & & \\
Cl & 103 & $\mathrm{mEq} / \mathrm{l}$ & & \\
Ca & 9.7 & $\mathrm{mg} / \mathrm{dl}$ & & \\
CRP & $<0.10$ & $\mathrm{mg} / \mathrm{dl}$ & & \\
LDH & 144 & $\mathrm{U} / \mathrm{l}$ & & \\
CK & 54 & $\mathrm{U} / \mathrm{l}$ & \\
T-SPOT tuberculosis-specific IFN & $(-)$ & \\
\hline
\end{tabular}

Although IMTs account for $20-50 \%$ of all pediatric primary lung tumors, they represent less than $1 \%$ of lung tumors in adults $[8,9]$. Because of uncertainty regarding the true biological origin of these tumors, other terms have been used to refer to IMTs such as plasma cell granuloma, xanthogranuloma, inflammatory myofibroblastic tumor, inflammatory pseudotumor, fibroxanthoma, and fibrous histiocytoma $[8,10]$. We emphasize that IMT of the lung is not uncommon in children.

\section{Clinical features}

The chief complaint in patients with pulmonary IMT is usually nonspecific, which makes the diagnosis difficult to confirm. IMT is asymptomatic in many patients, whereas respiratory tract infection-related symptoms, such as cough, shortness of breath, chest pain, or complaints of fatigue, fever, and weight loss, are common in others. There are no reports of IMT in children with pneumothorax. It is difficult to consider IMT in the lung for preoperative diagnosis as in our case, and imaging findings might be one of the diagnostic cofactors that consider IMT for differential diagnosis. Although there are no characteristic imaging findings in IMT, calcification is relatively common in IMT occurring in children. Hamartoma is often suspected if calcification is seen in a mass lesion of the lung, but this is rare in children. Therefore, IMT is one of the differential diseases when a mass lesion suspected of calcification is found in children [11].

Laboratory examinations in most instances of IMT are normal, but anemia, thrombocytopenia, and an elevated sedimentation rate may be revealed. Radiographically, pulmonary IMT usually occurs as a single nodule or a mass with clear boundaries and slight to moderate homogeneous contrast enhancement; however, occasionally, IMT may mimic malignant tumors [5]. According to previous reports, the incidence of multiple nodules 


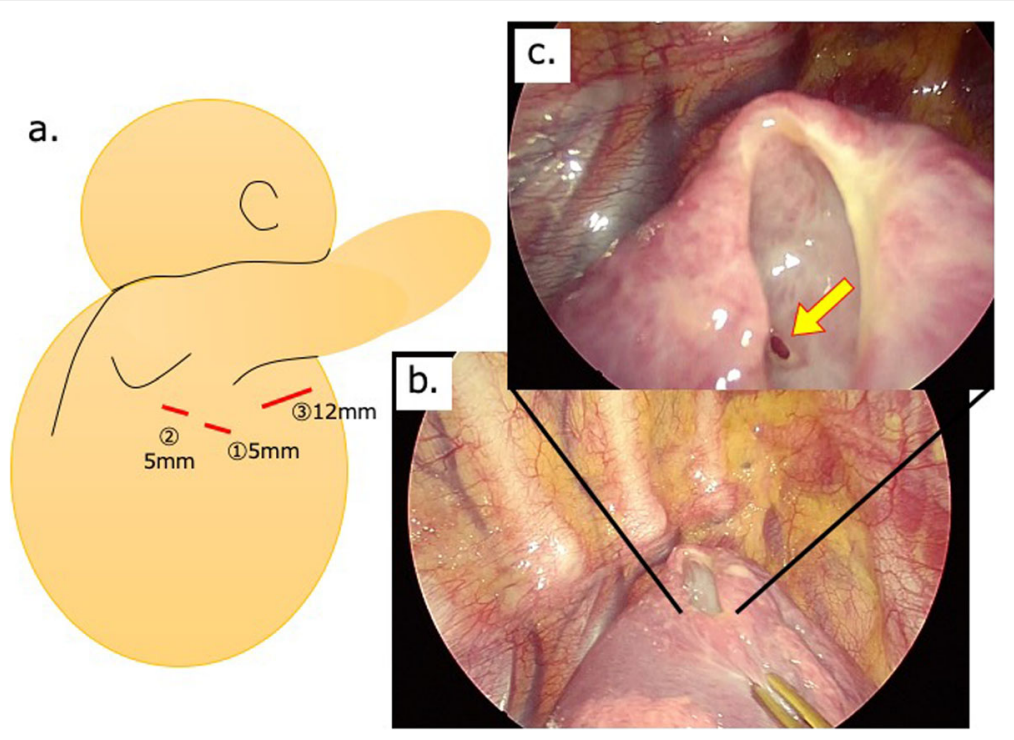

Fig. 3 Operative findings. a Thoracoscopic partial resection of the right upper lobe showing the three ports: (1), (2), and (3). We inserted a 5-mm port on the mid-axillary line at the sixth intercostal space (1), followed by a $5-\mathrm{mm}$ port inserted on the posterior axillary line at the sixth intercostal space (2), and a 12-mm port on the anterior axillary line at the fourth intercostal space (3). $\mathbf{b}$ The cyst wall is partially ruptured in the upper right lobe (S1-2). c An opening to the bronchiole was confirmed in the cyst wall (yellow arrow)

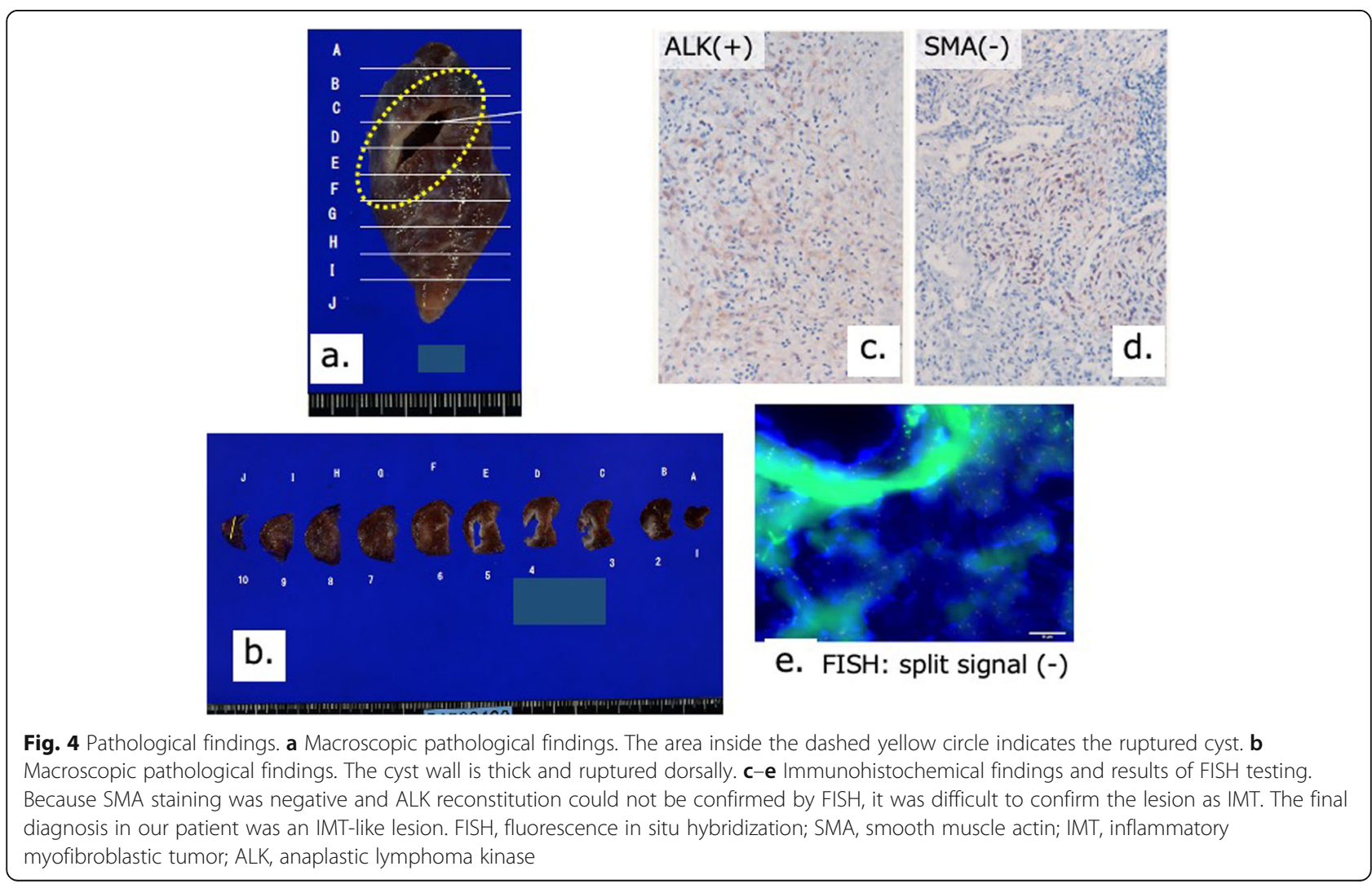


accounts for $5 \%$ of pulmonary IMTs [12]. In the current case, the patient complained of dyspnea, and imaging findings showed a cystic lesion with thickened walls on chest X-ray and chest computed tomography.

\section{Pathological findings}

IMTs are rare neoplasms composed histopathologically of differentiated myofibroblastic spindle cells accompanied by inflammatory cells [13]. Rearrangements involving the ALK locus on chromosome 2p23 have been discovered in $50 \%$ of patients with IMT $[14,15]$.

Pulmonary IMT rarely occurs in the neonatal or infantile period [16, 17], although IMT is one of the most common pulmonary tumors in older children [7]. Histological examination of typical pediatric pulmonary IMTs reveals fascicles of myofibroblastic cells admixed with an inflammatory infiltrate consisting of lymphocytes, plasma cells, and eosinophils [7]. Histological analysis of these tumors in older children reveals fascicles of spindle cells, which are consistent with IMT, but with little inflammatory infiltration $[18,19]$. Coffin et al. reported the immunohistochemical analysis of IMT in which immunoreactivity for muscle-specific actin (89\%) and smooth muscle actin (92\%) varied from a focal to a diffuse pattern in the cytoplasm of spindle cells; generally, smooth muscle actin staining was more prominent than musclespecific actin reactivity [6].

\section{Treatment}

Liu et al. [5] reported that, in general, IMT patients who are candidates for surgical resection have a favorable prognosis, with 5- and 10-year survival rates of $91 \%$ and $77 \%$, respectively [20]. Nevertheless, approximately $8 \%$ of pulmonary IMTs without indications for surgery have a continuous growth pattern, with $5 \%$ of patients at risk of developing distant metastasis [18]. Distant metastases appear mainly in ALK-negative IMTs, but local recurrence occurs regardless of ALK expression [6]. In a study involving 44 patients, Kovach et al. demonstrated an $8 \%$ recurrence rate with a primary surgical approach and proposed surgical resection of all lesions if there are no contraindications related to the patient's anatomy or morbidity [21].

Regarding inoperable patients, including patients with unresectable recurrence or metastasis, therapeutic approaches, such as steroids, nonsteroidal antiinflammatory drugs, chemotherapy, and radiotherapy, provide unsatisfactory effects [5]. One report described using steroids or nonsteroidal anti-inflammatory drugs with a combination of epirubicin, dacarbazine, and docetaxel or vinorelbine plus methotrexate, programmed cell death ligand-1, and apatinib [5].

\section{Conclusion}

In conclusion, IMTs are not uncommon in children; therefore, IMT should be considered as a diagnosis if children or young adults develop spontaneous pneumothorax.

\section{Abbreviations}

ALK: Anaplastic lymphoma kinase; IMT: Inflammatory myofibroblastic tumor; SMA: Smooth muscle actin

\section{Acknowledgements}

We thank Jane Charbonneau, DVM, and Sarah Williams, PhD, from Edanz Group (www.edanzediting.com/ac) for editing a draft of this manuscript.

\section{Authors' contributions}

$\mathrm{HM}, \mathrm{DI}, \mathrm{MH}, \mathrm{SY}$, and KM performed the surgical procedure. HM and KM contributed to the drafting of the manuscript and the literature review. NT and TS managed the patient's preoperative and postoperative course. MT, $M T$, and $Y T$ contributed to the pathological examination. HM and KM contributed to the critical revision of the manuscript. All authors read and approved the final manuscript.

\section{Funding}

None.

Availability of data and materials Not applicable.

Ethics approval and consent to participate

Not applicable.

\section{Consent for publication}

Written informed consent was obtained from the patient for publication of this case report and any accompanying images.

\section{Competing interests}

The authors have no competing interests to declare.

\section{Author details}

${ }^{1}$ Division of Pediatric Surgery, Department of Surgery, Asahikawa Medical University, 2-1-1-1 Midorigaoka Higashi, Asahikawa 078-8510, Japan.

${ }^{2}$ Respiratory Center, Asahikawa Medical University, 2-1-1-1 Midorigaoka Higashi, Asahikawa 078-8510, Japan. ${ }^{3}$ Department of Pediatrics, Asahikawa Medical University, 2-1-1-1 Midorigaoka Higashi, Asahikawa 078-8510, Japan. ${ }^{4}$ Department of Pathology, Asahikawa Medical University, 2-1-1-1 Midorigaoka Higashi, Asahikawa 078-8510, Japan. ${ }^{5}$ Department of Pathology, Kanagawa Children's Medical Center, Yokohama 232-8555, Japan.

Received: 10 April 2020 Accepted: 14 May 2020

Published online: 24 May 2020

\section{References}

1. Fletcher CD, Bridge JA, Pancras CW, editors. World Health Organization classification of tumours of soft tissue and bone. Lyon. (France): IARC Press; 2013

2. Al-Obaidi A, Buess C, Mogire J, et al. Inflammatory myofibroblastic tumor of the lung: an extremely rare condition in adults. Cureus. 2019;11(12):e6432. https://doi.org/10.7759/cureus.6432.

3. Melloni G, Carretta A, Ciriaco P, et al. Inflammatory pseudotumor of the lung in the adults. Ann Thorac Surg. 2005;79:426-32.

4. Cerfolio RJ, Allen MS, Nascimento AG, et al. Inflammatory pseudotumor of the lung. Ann Thorac Surg. 1999;67:933-6.

5. Liu Q, Wei J, Liu X, et al. Anaplastic lymphoma kinase-negative pulmonary inflammatory myofibroblastic tumor with multiple metastases and its treatment by apatinib: a case report. Medicine (Baltimore). 2019;98(52):e18414.

6. Coffin CM, Watterson J, Priest JR, et al. Extrapulmonary inflammatory myofibroblastic tumor (inflammatory pseudotumor). A clinicopathologic and immunohistochemical study of 84 cases. Am J Surg Pathol. 1995;19:859-72. 
7. Tanaka M, Kohashi K, Kushitani K, et al. Inflammatory myofibroblastic tumors of the lung carrying a chimeric A2M-ALK gene: report of 2 infantile cases and review of the differential diagnosis of infantile pulmonary lesions. Hum Pathol. 2017;66:177-82. https://doi.org/10.1016/j.humpath.2017.06.013 Epub 2017 Jul 11.

8. Sagar AES, Jimenez CA, Shannon VR. Clinical and histopathologic correlates and management strategies for inflammatory myofibroblastic tumor of the lung. A case series and review of the literature. Med Oncol, 35. 2018, 4;35(7): 102. doi: 10.1007/s12032-018-1161-0.

9. Barbetakis N, Efstathiou A, Xenikakis T, et al. An unusual cause of haemoptysis in a young male. Int Semin Surg Oncol. 2006;3:6

10. Gleason BC, Hornick JL. Inflammatory myofibroblastic tumours: where are we now? J Clin Pathol. 2008;61:428-37.

11. McHugh K; Benign pulmonary tumors. In Carty $\mathrm{H}$ (ed): Imaging children (2nd).pp 1152-1153, Churchill Livingston, 2004

12. Narla LD, Newman B, Spottswood SS, et al. Inflammatory pseudotumor. Radiographics. 2003;23:719-29.

13. Villalobos VM, Camidge DR. Targeting ALK in inflammatory myofibroblastic tumours. Lancet Respir Med. 2018;6:405-7.

14. Cook JR. Anaplastic lymphoma kinase (ALK) expression in the inflammatory myofibroblastic tumor: a comparative immunohistochemical study. Am J Surg Pathol. 2001:25:1364-71.

15. Coffin CM, Hornick JL, Fletcher CDM. Inflammatory myofibroblastic tumor: comparison of clinicopathologic, histologic, and immunohistochemical features including ALK expression in atypical and aggressive cases. Am J Surg Pathol. 2007;31:509.

16. Mergan F, Jaubert F, Sauvat F, et al. Inflammatory myofibroblastic tumor in children: clinical review with anaplastic lymphoma kinase, Epstein-Barr virus, and human herpesvirus 8 detection analysis. J Pediatr Surg. 2005;40:1581-6.

17. Siminovich M, Galluzzo L, Lopez J, et al. Inflammatory myofibroblastic tumor of the lung in children: anaplastic lymphoma kinase (ALK) expression and clinico-pathological correlation. Pediatr Dev Pathol. 2012;15:179-86.

18. Owusu-Brackett N, Johnson R, Schindel DT, et al. A novel ALK rearrangement in an inflammatory myofibroblastic tumor in a neonate. Cancer Genet. 2013;206:353-6.

19. Sirvent N, Hawkins AL, Moeglin D, et al. ALK probe rearrangement in a t $(2$; 11;2)(p23;p15;q31) translocation found in a prenatal myofibroblastic fibrous lesion: toward a molecular definition of an inflammatory myofibroblastic tumor family? Genes Chromosomes Cancer. 2001;31:85-90.

20. Fabre D, Fadel E, Singhal $S$, et al. Complete resection of pulmonary inflammatory pseudotumors has excellent long-term prognosis. J Thorac Cardiovasc Surg. 2009;137:435-40

21. Kovach SJ, Fischer AC, Katzman PJ, et al. Inflammatory myofibroblastic tumors. J Surg Oncol. 2006:94:385-91.

\section{Publisher's Note}

Springer Nature remains neutral with regard to jurisdictional claims in published maps and institutional affiliations.

\section{Submit your manuscript to a SpringerOpen ${ }^{\circ}$ journal and benefit from:}

- Convenient online submission

- Rigorous peer review

- Open access: articles freely available online

- High visibility within the field

- Retaining the copyright to your article

Submit your next manuscript at $\boldsymbol{\nabla}$ springeropen.com 